\title{
Trauma: an ideology in search of evidence and its implications for the social in social welfare
}

Mark Smith

Sebastian Monteux

Claire Cameron

This is an Accepted Manuscript of an article published by Edinburgh University Press in Scottish Affairs. The Version of Record is available online at:

http://www.euppublishing.com/doi/abs/10.3366/scot.2021.0385

Smith, M., Monteux, S. \& Cameron, C. (2021) 'Trauma: an ideology in search of evidence and its implications for the social in social welfare. Scottish Affairs, 30(4): pp.472-492. DOI: $10.3366 /$ scot.2021.0385 


\title{
Trauma: an ideology in search of evidence and its implications for the social in social welfare
}

\author{
Mark Smith, Sebastian Monteux and Claire Cameron
}

\begin{abstract}
A recent special issue of this journal focussed on the emergence of the Adverse Childhood Experiences (ACEs) movement as a key driver of Scottish social policy. In this article, we extend the critiques advanced therein by locating ACEs within a wider cultural turn towards psychological trauma which, over the past decade, has become reified as a master theory across social welfare. Yet, the concept is insubstantial and ill-defined, and the claims made for policy based upon it are at best disputable. Its prominence is less evidence-based than it is testimony to how a particular (cultural and professional) ideology, regardless of its intellectual merit, can be insinuated into policy discourse. ACEs, we suggest, is utilised to provide the trauma paradigm with some ostensibly quantifiable substance. We illustrate our argument through reference to the Scottish Government's National Trauma Training Programme (2020). We go on to consider some of the implications of such ideological capture for the direction of Scottish social welfare policy and practice. The prominence given to trauma perspectives has potentially iatrogenic consequences for those identified or self-identifying as traumatised. At a wider level, it reflects a professional and epistemic privileging of a narrow, ostensibly therapeutic, worldview which, in turn, acts to marginalise 'the social' that characterised erstwhile Scottish approaches to welfare.
\end{abstract}

Keywords: trauma; ACEs; Scotland; policy; social welfare

Mark Smith is Professor of Social Work, University of Dundee; Sebastian Monteux is Lecturer in Mental Health Nursing, Abertay University; Claire Cameron is Professor of Social Pedagogy, Thomas Coram Research Unit (TCRU), University College London 


\section{Introduction}

Murray and Hunter Blackburn (2019) use the concept of policy capture, where policy is directed away from the public interest towards a specific interest (OECD, 2017), to discuss Scottish Government policy-making in respect of proposed changes to the Gender Recognition Act (2004). In this article, we suggest that the notion of policy capture might be applied more widely in Scottish social welfare. In an effort to portray Scotland as a progressive European nation, the Scottish Government has been captured by interest groups that wish to place trauma and the need for a compassionate response to it at the heart of social policy. Our position in this article is that trauma does not offer a sufficiently strong foundation for social policy; it is not evidence-based as is purported but reflects a particular ideological position on the relationship between past and present.

In recent years, trauma has become fundamentally intertwined with the Adverse Experiences (ACEs) studies that are the focus of a recent special issue of this journal (Scottish Affairs, 29(4), 2020). An ACEs narrative increasingly conflates with the debate about preventing and responding to trauma (Spratt et al, 2019; Early Intervention Foundation, 2020). ACEs and trauma are cut from the same cloth in terms of how they seek to understand the present from the past. Spratt and Kennedy (2020) identify trauma as one of the conceptual pillars of ACEs. We reframe the direction of this linkage to suggest that ACEs is more accurately a pillar that is necessary to support a wider trauma paradigm. This precedes the discovery and indeed the more recent rediscovery of ACEs and, on its own merits, is remarkably lacking in substance. The trauma and ACEs lobbies both speak of kindness, compassion and even love as being all that is required to furnish social policy with a full set of improved wellbeing outcomes. The certainty and the moral rectitude with which they do so reflects 'a system talking to itself', a 'magic circle' at the heart of civic Scotland consisting of charities, directors, managers and academics, all of which are often recipients of Scottish Government funding (McGhee and Waterhouse, 2019). The result is a reductionist view of social welfare in which social scientific perspectives are largely absent.

While the contributions to the ACEs special issue offer a necessary corrective to the headlong rush to make Scotland the world's first ACE Aware nation (Ace-Aware Scotland, 
2017), they leave the concept of trauma, which as we suggest undergirds the ACEs discourse, untouched. In this conceptual critique, we question the basis, utility and ethics of the status that trauma has assumed in culture and social policy. Davidson, Critchley and Wright (2020), in their editorial to the Scottish Affairs special issue, make the case that future research into ACEs must take into account the experiences of practitioners (and service users). We engage in this critique as experienced practitioners in social work, education and mental health, now academics in our respective fields. We begin the article by offering a quick introduction to ACEs to contextualise our argument.

\section{What are ACEs?}

The ACEs movement originated in the US following a large-scale health study of 17,000 participants (Felitti et al, 1998). The study's participants, all members of the health insurance company Kaiser Permanente, were mostly of white, middle- and upper- middle class, college level educated, in employment and - by definition - with access to private health care. The study sought to explore the relationship of ACEs to adults' physical and mental health and behaviours. It identified ten ACE categories including: emotional, physical, and sexual abuse, emotional and physical neglect, witnessing domestic violence, growing up with mentally ill or substance abusing household members, loss of a parent, or having a household member incarcerated (Larkin and Park,. 2012). These experiences are said to cause what is termed 'toxic stress', which Levenson (2017) links with trauma. A score out of ten adverse experiences is given depending on the number of positive answers. The presence of even one ACE is said to correlate with deleterious outcomes but a score of four or more is said to show a strong relationship to a range of health and social problems throughout the life-course, ranging from social, emotional and cognitive impairment through disease, disability and social problems through to early death (Bellis et al 2016). Critiques of the reductionist potential of this equation are made in the ACEs special issue in this journal (2020) and in a special issue of Social Policy and Society (Edwards et al, 2019) and we won't repeat these here. Rather, we turn our attention to the linkage between ACEs and a wider cultural turn towards trauma. 
It is important to state that our position does not seek to ignore or divert from the reality and the cumulative effects of adversity in children's lives or that this may have lasting impact. Indeed, the eminent child care academics, Parker and Bullock (2017: 309) in their review article on disadvantage experienced by children note, without reference to concepts of trauma or ACEs, that 'if a disadvantage is severe it is generally multiple. If it is multiple it is generally severe'. They cite Rutter et al.'s work, from as far back as 1979, on the mental health of young people, which showed that each additional disadvantage compounds the severity of the overall problem and that it does so exponentially. Counting the number of ACEs or re-naming disadvantage as trauma tell us nothing we should not already know. What it does do is place the debate in an individualised, psychological frame.

While, occasionally, childhood disadvantage may involve egregious inter-personal violence. it can, mostly, be attributed to material and/or social circumstances (Featherstone et al, 2018). Whatever the cause or circumstances, whether inter-personal or structural, it is proper that abuse should be called as wrong and a restorative position taken on it. But there is a need to separate what is morally wrong from what is inevitably harmful. It is equally wrong that those who experience disadvantage or abuse should suffer the double jeopardy of assumed life-long trauma if not rescued by some kindly teacher, social worker or, increasingly, police officer prepared to build a relationship with them (parents have less of a role in this because the family home is identified as the site of many of the adverse experiences enumerated in the ACEs framework). The trauma paradigm both feeds and depends upon the growth of ACEs and it demands interrogation.

We begin this critique by probing the emergence and growth of trauma theory, identifying it as a social construct rather than a scientific reality. We go on to chart the linkage of ACEs to trauma in Scotland and outline the lack of evidence for the trauma-informed approaches that are advocated. Despite this lack of evidence, the Scottish Government has invested heavily in a new trauma training package, of which we will offer a preliminary critique. We go on to identify the cultural and political context that has provided fertile ground for the trauma paradigm to seed and how Scotland's current political positioning leaves it open to this. This turn to trauma is not necessarily progressive but has a number of potentially deleterious consequences for people so labelled and for the nature of care practice. At a 
wider level, as an approach to social welfare, trauma evinces a neoliberal worldview that expunges much of 'the social' from how disadvantage and welfare are understood and responded to.

\section{Trauma}

While the idea of trauma has become naturalised in everyday assumptions about the impact of the past on the present, it has not always been understood in this way. The term derives from the Greek word for a somatic wound (Luckhurst, 2013). It has been extended and employed to make sense of the psychic effects of cataclysmic events such as the Holocaust or the horrors of war or disaster, which quite understandably may leave a legacy on those who experienced them. Again, we are not contesting that body and mind react to severe events but question the employment of trauma as an all-encompassing paradigm to explain this.

Trauma theory, as distinct from the original medical understandings of trauma, has emerged in recent decades. It can be traced back to a turn in the humanities and, in particular, to the work of a literary scholar, Cathy Caruth (1996), who postulated that because past experience can be unbearable in its horror and intensity, it often exists as memories that are not immediately recognizable as linking to a particular event; trauma is marked by the absence of 'traces' or witnesses. A notion of latency exists between an event and later reaction to it that makes the experience qualify as trauma; it involves looking back and interpreting or reinterpreting the past. Representations of a traumatic episode, thus, bear only an indirect, highly mediated relation to external reality (Radstone, 2007). Trauma is not scientific, as can be posited in current discourse, but interpretative. With its focus on adversity, trauma came to resonate but also to drive the therapeutic turn that has exerted such a cultural influence in recent decades (Furedi, 2003; Madsen, 2014). Its existence is said to be attested in physical or psychological symptoms such as flashbacks and night terrors, the roots of which can be 'discerned' by skilled therapists or those prepared to act as a 'witness'. It is this process of 'witnessing' to the testimony of a traumatic experience that is claimed to allow 'recovery' from it. The therapist, thus, becomes the key figure 
discerning and mediating trauma's absent traces. This becomes problematic, firstly because therapists are reluctant to deny the reality of traumatic testimony and therefore must accept testimonies as being 'true' and, secondly, because it opens the possibility of therapists appropriating victim stories (Radstone, 2007; Luckhurst, 2013).

Radstone (2007: 9) argues that 'although trauma theory's subject matter-the sufferings of others-makes critique difficult, the theory's politics, its exclusions and inclusions, and its unconscious drives and desires are as deserving of attention as those of any other theory'. She goes on to say that the political and cultural contexts within which trauma theory has risen to prominence have remained largely unexamined. We proceed here to trace some of this context.

\section{Trauma creep}

The influence of what has become a therapeutic trauma paradigm mushroomed from its origins in the humanities to the extent that Fassin and Rechtman (2009) identify an 'empire of trauma'. This was consolidated in medical and public understandings through the inclusion of its symptomology, codified as Post-Traumatic Stress Disorder (PTSD), in The Diagnostic and Statistical Manual of the American Psychiatric Association (APA). Over the period from first inclusion in the DSM in 1980, symptoms have been added to the definition of PTSD, but the APA also went beyond enumerating symptoms to identify what constitutes a traumatic event (APA, 2013). This development makes the questionable shift from seeing trauma not as an interpretative or psychological response to a past experience, to assume that certain events are, in and of themselves traumatic, even though the fact that people can respond differently to the same experience might cast doubt upon such an assumption. APA definitions have, over time, seen the widening of the definition to include witnessing others' trauma, and historical, inter-generational trauma. Through a process of 'concept creep' (Furedi, 2016; Haslam, 2016), trauma's reach has extended from being lifethreatening to a point where difficult or untoward (but often everyday) events become identified as, not merely uncomfortable or distressing but traumatic. Trauma discourse is 
now replete with metaphors of psychic scars and mental wounds (Haslam and McGrath, 2020).

Bath (2017: 2) notes that 'in the space of little more than a decade, trauma has emerged as the dominant theoretical framework in human services'. He also highlights the confusion in definitions of trauma, which differ as to whether it is said to refer to an adverse event or circumstance, the way an individual experiences such an event or the harm assumed as a result of an experience. Definitional difficulties are compounded by prevalence studies, which show rates that can range between 4\% and 71\% (Finkelhor et al, 2015; McLaughlin et al, 2013; Saunders and Adams, 2014).

Trauma's lack of definitional clarity, and the inability to pin down prevalence or incidence, might in other circumstances, be argued to compromise the ability to say that something exists (Hacking, 1992). However, the tenuous and indirect link from past to present as postulated in trauma discourse has in recent years, as with other areas of social welfare, been claimed to be bolstered by neuroscience (Wastell and White, 2017). Neuroscience is called upon to evidence trauma's absent traces and its psychic wounds. As Munro and Mushold (2014) note, neuroscience offers a persuasive rhetorical device which can, and is perhaps intended to, foreclose intelligent debate. Plafky (2016) charts how, in social welfare, complex neuroscientific concepts are simplified and translated by 'knowledge entrepreneurs' within the training community. In this world, trauma's impact on brain development is presented as established fact. Yet, the reality is that, even if such neurological links do exist, they are likely to be far more complex than is accommodated in popularised understandings (Wastell and White, 2017) and they certainly do not offer a blueprint of what to do next that goes beyond what we should already know about good care.

If trauma as a psychological construct is so hard to define through reference to medical science, then we are drawn back to understanding it through the cultural scripts that people individually and collectively employ to make sense of past experience. This redirects attention from the nature of events identified as traumatic to their representation and the role of cultural mediators and scripts in that process (Alexander et al., 2004). This renders 
trauma less an empirically validated diagnostic category than a highly malleable hermeneutic tool, employed for making meaning in the present by reference to the past (Lambek \& Antze, 1996). In this sense it has become, as Gone (2009) argues, a folk discourse, one that is taken up by particular groups at particular times according to shifts in the broader social recognition of forms of victimhood to become a resource for those who suffer, 'a tool used in a demand for justice' (Fassin \& Rechtman, 2009: 279) and a call on resources and for financial compensation (Furedi, 2016). In valorising victimhood, it is politically difficult to dispute and is employed to elicit public sympathy but also to push simplistic and often punitive policy agendas.

\section{ACEs and trauma}

In a Scottish context, the link between ACEs and trauma was made apparent in a lecture to the Glasgow Centre for Population Health, given by Jane Stevens, Founder of the US-based ACEs Connection Network. The lecture was entitled, 'How ACEs and the "Theory of Everything" Can Help Build Healthy Communities'. Stevens' 'Theory of Everything' is described as a 'unified science' of human development, an understanding of which 'will have a profound impact on our lives, and already is, in astounding ways'. Stevens goes on to attest that 'Based on this research, people, organizations and communities are putting into place trauma-informed and resilience-building practices that are already showing remarkable results, as long as those practices integrate an understanding of ACEs' (GCPH, 2016). In this statement we see the clear (although circular) connection made between ACEs and trauma; ACEs requires being trauma-informed and being trauma-informed only works so long as it integrates an understanding of ACEs.

\section{How are we to deal with trauma?}

Trauma is said to require an approach to practice that is trauma-informed. Just what this entails is as loose as trauma itself. Bath (2008) identifies three pillars of trauma-informed care (TIC): safety, connections, and managing emotional impulses. The US Substance Abuse 
and Mental Health Services Administration (SAMHSA, 2014), rather circularly, defines a trauma-informed approach as 'a program, organization, or system that realizes the impact of trauma, recognizes the symptoms of trauma, responds by integrating knowledge about trauma policies and practices, and seeks to reduce re- traumatization'. In a UK context, Sweeny and colleagues (2016:17) state, again circularly, that 'in a trauma-informed service, it is assumed that people have experienced trauma'. According to such formulations, trauma self-evidently exists and needs to be responded to in order to confirm its existence.

The SAMHSA (2014) document identifies four key elements of a trauma-informed approach, which include workforce development, practice change and use of evidence-based practices (EBPs), trauma screening, and inter-system collaboration and communication. Such general descriptions offer no tangible pointers as to how one might go about offering TIC or what might differentiate it from common or garden care. Indeed, most of the principles of TIC are, as Berliner and Kolko (2016: 169) recognise, 'essentially principles of good care and are not specific to trauma'. For example, Wilton and Williams (2019), in their study of TIC for women identify what are no more than basic social work principles as the characteristics of TIC. Similarly, the National Institute for Clinical Excellence (NICE) guidelines (2018) - noting the absence of good quality evidence to support trauma-informed approaches - identify generic principles of constancy, reliability, individual preferences/sensitivities, underscoring a position that good mental health practice is humanistic and sensitive rather than overtly clinical.

Proponents of a trauma discourse might argue that a focus on trauma foregrounds the role of adverse social circumstances over poor individual life-choices as a determinant of social suffering. However, as with any discourse that seeks to classify people, framing forms of suffering in a particular way has real effects on people's lives, through shaping the way that they understand themselves and others (Hacking, 2007). Establishing a category requires that it be populated, which might raise a concern about trauma propagating itself. One might ponder, for instance, whether the current concern over adolescent mental health reflects an actual increase in mental ill-health or whether it might just give a name and a set of symptoms that young people can apply to make sense of everyday adolescent angst? In this sense trauma may be iatrogenic, a product of the dominant diagnostic and cultural 
categories and the power of the professional groupings that peddle these. This is not an enlightened or progressive development but one that might bring about the very symptoms of mental ill-health it is intended to mitigate (Lukianoff and Haidt, 2015).

In many senses, the prominence given to trauma evokes a degraded image of the human subject as hopeless, lacking agency and prey to external events beyond their control. As Haslam and McGrath (2020:525-26) note:

By supposing that the main determinants of our lives are external, uncontrollable, severe, and even irreparable - severity and permanency, embodied in the metaphor of the scar, being two common assumptions about the nature of trauma - it may encourage a sense of helplessness, pessimism, and defeat

Seeking to understand the past through a singular lens of trauma limits the cultural scripts available to people to do so in alternative, more adaptive and hopeful ways. Haslam and McGrath (2020) argue, life's challenges might be better overcome if placed in a different interpretive frame.

\section{The evidence (or lack thereof) for trauma-based approaches}

As we report above, Jane Stevens claims that TIC, informed by an understanding of ACEs, is showing remarkable results. The problem with this assertion is that evidence is nowhere to be seen. In response to concern about the empirical basis of TIC, Hansen and Lang (2016: 99) edited a special issue of the journal Child Maltreatment, issuing a call for papers addressing empirical studies on trauma-informed care. They reflect: '( $p$ )erhaps not surprisingly, we did not receive an influx of papers ...' and speculate that:

this could be due to our emphasis on empirical research rather than just broad descriptions of TIC efforts. It is also noteworthy that none of the papers received or accepted for publication provided data that specifically examined the relationship between TIC and youth outcomes nor the costs or benefits of TIC ... 
They concluded that without this kind of evidence 'we may continue down a path which intuitively makes sense and is filled with good intention but lacks empirical support ...' (2016: 99). Bath (2017: 7) similarly suggests that trauma-informed programmes 'may have strong anecdotal support and clinical utility but they are frequently afforded a scientificallyproven status they have not yet earned'. Perhaps most tellingly, a systematic literature review of trauma-informed approaches in schools was conducted for the Campbell Collaborative. The researchers looked for studies that assessed the effects of traumainformed approaches, but, despite broad search criteria, no studies met the inclusion criteria. The authors concluded:

We simply do not have the evidence (yet) to know if this approach works, and indeed, we also do not know if implementing trauma-informed approaches in schools could have unintended negative consequences for traumatized youth and school communities.

(Maynard et al, 2019: 3).

A Review of Australian youth justice services (Armytage and Ogloff, 2017) introduces further dimensions to critiques of TIC. It notes that '(a)s a model of care, however, trauma-informed care is a complex therapeutic concept and approach that cannot be easily or readily translated into custodial settings or even community supervision and management' (2017: 48). It makes a telling point (which is of particular relevance in the light of the proposal we come to about trauma being everyone's business) that:

The Review is not convinced that staff sufficiently understand, nor can put into practice, the essential elements of what is fundamentally a clinical approach to a therapeutic intervention. Further, it has in fact resulted in a lessening of efforts that more directly focus on reducing offending because it establishes a preconception that all young offenders are victims of significant trauma. (Armytage and Ogloff, 2017: 48). 
In a Scottish context, Couper and Mackie (2016) are somewhat equivocal in reporting on ACEs studies, noting that (italics added):

It has been suggested that altered responses to stress can lead to physical changes in the way the brain develops. This is often referred to as 'toxic stress' and is thought to have an effect on how someone adapts to future adverse experiences and in the chance of developing health harming behaviours. (Couper and Mackie, 2016: 13)

Furthermore, Smith's (2018) review of ACES informed educational interventions for the Scottish Parliament found that papers reporting on the impact of interventions tended not to rigorously establish causality between activities to support young people with ACEs and any positive outcomes identified.

Despite the lack of evidence for the claims made for ACEs, Stevens' rhetoric was endorsed politically by Scotland's First Minister, Nicola Sturgeon, who identified ACEs as one of the key challenges in public health. The Scottish Government (2017) set out to 'embed a focus on preventing ACEs and supporting the resilience of children and adults in overcoming early life adversity across all areas of public service, including education, health, justice and social work'. Sturgeon's political imprimatur was cemented by a new National Training Programme, announced by John Swinney, Deputy First Minister, at a cost of $£ 1.35$ million, to support front line workers in responding to trauma (and ACEs) to be led and coordinated by NHS Education for Scotland (NES).

\section{The National Training Programme}

Co-terminus with the emerging interest in ACEs the Scottish Government, in 2016, asked NHS Education for Scotland (NES) to develop a set of resources to promote and implement TIC within Scotland. The Transforming Psychological Trauma: Knowledge and Skills framework (NES, 2017), alongside the Scottish Transforming Psychological Trauma Training Plan (2019), come together as part of the Scottish Government's commitment to developing a National Trauma Training Strategy as outlined in the Survivor Scotland Strategic Outcomes and Priorities (2015-2017) (Scottish Government, 2015) (NES, 2017: 7). These documents, alongside additional training resources, form the basis of the new National Trauma Training 
Programme (2020). The origins of the trauma responses in the Scottish Government funded Survivor Scotland organisation reinforces Gone's (2009) view of trauma reflecting a particular form of victimhood, in this case one with its origins in responses to sexual abuse now broadened to include any troubled relationship with the past. This is presented as a morality tale in the Ministerial Foreword to the Transforming Psychological Trauma Knowledge and Skill Framework by Maureen Watt (then Minister for Mental Health). In her Introduction, and reflecting an inter-personal rather than a structural view of trauma, she claims that:

We now understand more about the high rates of trauma and abuse in society, and for this we must commend the bravery and courage of people who have spoken out about their experiences of having lived through terrible events and been subject to horrific crimes, often behind closed doors. (NES, 2017:4)

Supplemented by various animations, videos, short training packages the National Training Programme aims to transform Scotland into a 'trauma-informed and responsive nation and workforce'. John Swinney, in his ministerial foreword of The Scottish Psychological Trauma Training Plan says that 'At its heart, this is about viewing your work through a "trauma lens"' (NES and Scottish Government, 2019).

The webpage for the national trauma training programme reinforces the link made between trauma and ACEs, identifying four key aims:

1. Providing inter-generational support for parents, families and children to prevent ACES

2. Reducing the negative impact of ACEs for children and young people

3. Developing adversity and trauma-informed workforce and services

4. Increasing societal awareness of trauma and adversity and supporting action across communities

The Programme Lead from NES states that there are two tag lines within the newly developed training Programme: 1) Trauma is everyone's business and 2) you do not need to 
be a trauma expert (NES, 2020a: 1). By this she means that the universal principles that underpin a trauma-informed approach, identified as empowerment, choice, collaboration, safety and trust are enough to support people. Again, these principles are not trauma specific and are no different to any other person-centred principles contained in a plethora of generic policies found across the Health and Social Care sectors.

Although a wider reference group was included in both the Knowledge and Skills Framework and the Training Plan, central to this commission were NES staff, almost exclusively clinical psychologists. The whole approach is predicated upon a psychological worldview. While there is passing but under-developed mention of poverty, there is little further attempt to offer any broader, alternative or social perspective.

A clinical orientation is also evident in the Plan's understanding of inter-personal relationships. Although much is made of the positive role these may have in mitigating trauma, this is understood from a clinical rather than an 'everyday' care orientation (Monteux and Monteux, 2020). The voice of user experience is co-opted to make the case for professional relationships to have 'a good level of neutrality' (NES, 2017: 26). Relationships are, thus, to be employed, not for their intrinsic human value but rather as therapeutic tools utilised/designed to overcome an individual's perceived deficits.

More broadly, 'lived experience' is called upon to fill the evidence gap that is otherwise absent in trauma approaches. And, while user experience is one legitimate form of knowledge and should be an ethical orientation that informs policy formulation, it should not substitute for other forms of knowledge or analysis (Atkinson, 2009).

Overall, we not only see the creep of a privileged psychological approach but, also, the dawn of a trauma 'master theory' that is to be at the heart of all training for the Scottish workforce for, as Swinney encourages, 'everyone has a role to play in understanding and responding to people affected by trauma' (NES, 2019). The case for such all-encompassing workforce development is premised on the statement that: 
(t)here is now widespread agreement that experiences of adversity and trauma are prevalent within our society and have the potential to significantly affect the quality of a person's life over the course of their lifetime, particularly where these experiences occur in childhood and are not buffered by supportive adults. (NES, 2019:2)

The introductory video for the Trauma Training Package talks of a 'burgeoning scientific revolution' (NES, 2020a: 1). Although across the two principal documents there are references to recommended reading and supporting documents, the evidence for this widespread agreement or for the scientific revolution is not made apparent through the kind of extensive literature review one might expect from a piece of work making such grand claims. The evidence to support the programme is taken (almost entirely) from the Welsh ACEs studies (Bellis et al, 2016); the other (Brown et al, 2009) is co-authored by Anda, one of the authors of the original ACEs studies, who has now rowed back on several key assertions of these (Walsh, 2020).

Premised on the notion of trauma being everyone's business, the workforce development strand of the National Training Plan, sets out its vision of a hierarchy of expertise from novice through 'trauma-informed' through to 'trauma specialist'. Trauma specialists, however these may be identified, are at the top. However, the assertion that trauma is everyone's business opens up the prospect of a workforce full of eager, caring individuals called upon to view their work through a trauma lens identifying an alarmingly large population of assumed traumatised people. This possibility is heightened as a result of the new mantra of the trauma movement - 'We want people to change the way they think about people's difficulties and ask not "what's wrong with you?" but "what has happened to you?"' If we were to take up this mantra, then every difficult thing that has happened to people could be reinterpreted as traumatic! We have the perfect mechanism to identify just about everyone as traumatised.

Our final point for the moment is to note a worrying development in which the National Training Programme asks organisations to sign up to The Leadership Pledge of Support, which: 
... asks senior leaders across Scotland, to provide a strong signal of leadership to our workforce that the delivery of trauma-informed care and practice across all services and sectors is a public health priority by signing up to the following public pledge of support. This pledge will demonstrate our shared commitment to adopting and embedding a long term, trauma-informed culture in Scotland to support anyone affected by psychological trauma. (NHS Education for Scotland, 2020b)

This is not benign or inconsequential. The inclusion of this pledge is clear in identifying the hegemony of a public health perspective in social policy. It also places irresistible pressures on organisations to sign it (and many are already parading their credentials as having done so). Any who are brave enough not to or who may operate to another, equally valid, model of care will be cast as unenlightened and retrogressive and this will likely filter through into commissioning decisions. This represents a troubling imposition of a singular worldview and insidious pressure to fall into line. And, as Haslam and McGrath (2020) caution, such a move precludes alternative ways of understanding or responding to adversity.

\section{Psychologising care}

The hierarchical nature of the proposed workforce framework is already evident in practice. Baron and Mitchell (2018), for instance, designate residential care workers in a Scottish secure unit, not as highly skilled experts in everyday care (Cameron, 2020) but as 'novice therapists' beholden to the real therapist, the trauma 'specialist', thus consolidating the role and status of such 'specialists' and, by extension, devaluing the role of those who provide everyday care. Yet, interestingly, the same desired outcome of emotional self-regulation sought by Baron and Mitchell does not require psychological intervention, but can, equally, be achieved in a socio-educational context through teaching philosophy to children in secure accommodation (Heron and Cassidy, 2018). It can presumably, also, be achieved through a host of other socio-educational activities and interactions.

A wider concern behind the privileging of the psychological worldview that trauma reflects a disciplinary land-grab. The stated aim of ACEs and trauma-based approaches is to create 'a 
culture of compassion in a psychologically informed society' (Couper and Mackie, 2016: 19). This reinforces the positioning of psychology as the academic discipline to deliver a compassionate society - not sociology, philosophy, anthropology, education or divinity, although each might equally lay claim to such an aspiration. This ambition reifies the shift from the soul to the psyche (Hacking, 1995) and the hegemony of what Rose (1996) calls psy-culture, whereby psychology has become fundamental in shaping the human condition in late modernity. In this sense, trauma has assumed the features of a secular religion, messianic in its ambitions and untroubled by doubt. The impact of trauma perspectives has already exerted a tangible impact on public policy. For example, the first Chair of the Scottish Child Abuse Inquiry, Susan O'Brien, was removed from her post because, according to Depute First Minister, John Swinney, she had revealed views which child abuse trauma experts had judged to 'indicate a belief system that is incompatible with the post of chair of such an inquiry' (Scottish Government, 2016). This is a worrying example of trauma trumping other legitimate perspectives (or 'belief systems'), such as legal process, in public policy and serves as a signifier of the power held by the trauma lobby and its mission to remove apostates.

\section{Discussion: the context of trauma's dominion in Scottish social policy}

We move on to seek some explanation as to how an ideology so devoid of evidence has become such a centrepiece of Scottish social policy. Loughlin (2002: 231) describes how, in policy formulation, 'terms are selected not for their substantive meaning but because they are seen to be "useful" to policy-makers ... Indeed, they are useful because their substantive meaning is so vague'. Trauma, because of its vagueness, is useful in conveying a sense of concern that chimes with the therapeutic zeitgeist. This is a global phenomenon that has found particularly fertile soil in Scotland. We go on to consider first the global and then the local in how we have got to this point.

The American historian, Christopher Lasch, arguably presaged the emergence of trauma as a central feature of cultural life in his book The Culture of Narcissism (1978) in which he argued that an increasingly liberal, secular, affluent and consumerist post-war America 
created the conditions for the narcissistic personality to come to the fore. A result of this has been the psychologising of politics (De Vos, 2010). This, Lasch claimed, led to political, academic or other traditional authority being usurped by solipsism, whereby personal experience became the primary prism through which to view the social world. This is evident in the current rhetorical vogue for drawing on 'lived experience' to bolster ideological claims. Presciently, Lasch recognised how this psychologising of the social origins of suffering acts to forestall more effective and lasting solutions to social problems.

A therapeutic ethos, with its emphasis on the self, came to align quite naturally with the neoliberal ideas of the New Right (Foster, 2016). As an institutional rationality, neoliberalism legitimises market-friendly, pro-globalisation economics combined with individualistic social and cultural policies. Fraser (2017) suggests that economic neoliberalism has been successful due to its malleability to be cloaked in progressive credentials. This could be a description of the Scottish National Party under Nicola Sturgeon's leadership. Trauma, with all its warm words, allows the pretense of being progressive and compassionate while sticking to the rules of the neoliberal game.

In practice contexts, a consequence of this loss of 'the social' as a lens through which to understand personal and collective experience has been the marginalisation of professions such as social work and community education which sought to understand individuals and groups in social context. These are replaced by a 'plethora of counselling, caring, coaching and managing activities that claim their stake on an increasingly liberalized welfare market' (Lorenz, 2008: 640). Trauma is particularly diffuse and free-floating in respect of its intellectual or professional affiliations (Fassin and Rechtman, 2009); it is, as the National Training Programme states, 'everyone's business' and one can become trauma-informed just by watching a few videos. This is to the detriment of the role that can and should be played by the social professions which, as Lorenz (2008: 641) notes, 'are mandated in a very particular way to relate life world processes to conditions at the level of the system'.

A troubling feature of current trauma discourse is that it is prone to trite national stereotyping such as, 'The real concern is that our (Scottish) culture does not recognise sufficiently the importance of warm, loving, secure relationships for children' (Zeedyck, 
2019). This assumption, without any supporting evidence, betrays a lacuna in respect of the relational tradition in Scottish society stemming from the Enlightenment (Hearn, 2016; Tronto, 1993) through the Scottish personal relations movement (Miller, 2008). At another, more structural, level, Paterson (2000) identifies the social and collective dimensions of Scottish social welfare through reference to the plethora of reforms in the 1960s, which saw the emergence of professions such as social work and community education and initiatives such as the children's hearings system, all of which understood that outcomes for children were not solely intra-familial but must be related to the social and economic circumstances they faced (Paterson, 2000). ACEs and trauma discourse seems oblivious to these strands in Scottish social welfare. They certainly don't bring us anything new or progressive to the table. Like other current policy initiatives, they offer form over substance (McGhee and Waterhouse, 2019).

\section{Conclusion}

We reiterate our position stated earlier in the article that past experience can have a deleterious impact on people and that there is a moral and political imperative to seek to avert and respond to this in helpful ways. The trouble with the current evangelism that surrounds ACEs and trauma is that adherents approach this imperative through a singular story, one based around what is an almost biblical vision of a community of 'care and love'. ACE-Aware Scotland (2017) raises the question that this aspiration might 'sound too emotional, too airy-fairy, too soft to ... seriously guide public policy-making and cultural regeneration'. It does because it is. The story advanced through a trauma discourse evinces a narrow, psychological and broadly 'therapeutic' worldview, which fails to appreciate alternative intellectual or professional perspectives, particularly those that express any level of social analysis or critique. Accordingly, there is little prospect of a trauma paradigm having any effect on deep-seated social problems. The fact that the Scottish Government seems to think it might, suggests its capture by interest groups. 


\section{References}

ACE-Aware Scotland (2017) http://aceawarescotland.com/vision/ [accessed $7^{\text {th }}$ December 2020]

Alexander, J. C., Eyerman, R. Giesen, B. Smelser, N.J. and Sztompka, P. (2004). Cultural trauma and collective identity. Berkeley: Univ of California Press.

American Psychiatric Association (2013). Diagnostic and Statistical Manual of Mental Disorders. 5th ed. American Psychiatric Association, Arlington: VA, USA.

Atkinson, P. (2009). 'Illness narratives revisited: the failure of narrative reductionism'. Sociological Research Online, 14(5), 196-205.

Barron, I. and Mitchell, D. (2019). 'The fairy tale model: Secure facility therapist perceptions'. Journal of child \& adolescent trauma, 12(2), 257-267.

Bath, H (2008). 'The Three Pillars of Trauma-Informed Care'. Reclaiming Children and Youth, 17(3), 17-21.

Bath, H. (2017). 'The Trouble with Trauma'. Scottish Journal of Residential Child Care, 16(1), 1-12.

Bellis, M.A., Ashton, K., Hughes, K., Ford, K.J., Bishop, J. and Paranjothy, S., (2016). Adverse childhood experiences and their impact on health-harming behaviours in the Welsh adult population. Public Health Wales NHS Trust.

Berliner, L. and Kolko, D. J. (2016). 'Trauma-informed care: A commentary and critique'. Child Maltreatment, 21(2), 168-72.

Brown, D. W., Anda, R. F., Tiemeier, H., Felitti, V. J., Edwards, V. J., Croft, J. B., \& Giles, W. H. (2009). 'Adverse childhood experiences and the risk of premature mortality'. American journal of preventive medicine, 37(5), 389-396.

Cameron, C. (2020). 'Towards recognising practitioners working in out-of-home care as experts in everyday life: A conceptual critique'. International Journal of Social Pedagogy, 9 (1)

Caruth, C., (1996). Unclaimed Experience: Trauma. Narrative, and History. Baltimore: Johns.

Couper S. and Mackie P. (2016). 'Polishing the Diamonds': Addressing Adverse Childhood Experiences in Scotland. Glasgow: Scottish Public Health Network.

Davidson, E., Critchley, A. and Wright, L.H. (2020). 'Making Scotland an ACE-informed nation'. Scottish Affairs, 29(4), 451-455. 
De Vos, J.(2010). 'Christopher Lasch's the culture of narcissism: The failure of a critique of psychological politics'. Theory \& Psychology, 20(4), 528-548.

Early Intervention Foundation (2020) Adverse childhood experiences: What we know, what we don't know, and what should happen next. https://www.eif.org.uk/report/adversechildhood-experiences-what-we-know-what-we-dont-know-and-what-should-happen-next [accessed $26^{\text {th }}$ July 2021]

Edwards, R., Gillies, V., \& White, S. (2019). 'Introduction: Adverse Childhood Experiences (ACES) - Implications and Challenges'. Social Policy and Society, 18(3), 411-414.

Fassin, D and Rechtman, R. (2009). The Empire of Trauma: An Inquiry into the Condition of Victimhood, Princeton, NJ: Princeton University Press.

Featherstone, B., Morris, K. and White, S. (2014). 'A marriage made in hell: Early intervention meets child protection'. British Journal of Social Work, 44(7), 1735-1749.

Featherstone, B. and Gupta, A. (2018). Protecting children: A social model, Bristol: Policy Press.

Felitti, V. J., Anda, R. F., Nordenberg, D., Williamson, D. F., Spitz, A. M., Edwards, V. \& Marks, J. S. (1998). 'Relationship of childhood abuse and household dysfunction to many of the leading causes of death in adults: The Adverse Childhood Experiences (ACE) Study'. American Journal of Preventive Medicine, 14(4), 245-258.

Finkelhor, D., Turner, H. A., Shattuck, A., \& Hamby, S. L. (2015). 'Prevalence of childhood exposure to violence, crime, and abuse'. JAMA Pediatrics, 168, 540-546.

Foster, R. (2016). 'The therapeutic spirit of neoliberalism'. Political Theory, 44(1), 82-105.

Fraser, N. (2017). 'From progressive neoliberalism to Trump-and beyond'. American Affairs, 1(4), 46-64.

Furedi, F. (2003) Therapy Culture: Cultivating Vulnerability in an Uncertain Age, London: Routledge.

Furedi, F. (2016). 'The cultural underpinning of concept creep'. Psychological Inquiry, 27(1), 34-39.

Glasgow Centre for Population Health (2016). Jane Stevens Lecture: 'How ACEs and the "Theory of Everything" Can Help Build Healthy Communities' https://www.gcph.co.uk/events/166 [accessed $27^{\text {th }}$ December 2020]

Gone, J.P. (2013). 'Redressing First Nations historical trauma: Theorizing mechanisms for Indigenous culture as mental health treatment'. Transcultural Psychiatry. 50(5), 683-706. 
Hacking, I. (1992) 'World-Making by Kind-Making: Child Abuse for Example', in Douglas M. and Hull D. (eds), How Classification Works: Nelson Goodman among the Social Sciences. Edinburgh: Edinburgh University Press, 180-238.

Hacking, I. (1995). Rewriting the Soul: Multiple Personality and the Sciences of Memory. Princeton, NJ: Princeton University Press.

Hacking, I. (2007). 'Kinds of people: Moving targets'. Proceedings-British Academy (151, 285). Oxford, Oxford University Press.

Haslam, N. (2016). 'Concept Creep: Psychology's Expanding Concepts of Harm and Pathology', Psychological Inquiry, 27(1), 1-17.

Haslam, N., \& McGrath, M. J. (2020). 'The creeping concept of trauma'. Social Research: An International Quarterly, 87(3), 509-531.

Hearn, J. (2016). 'Once more with feeling: The Scottish Enlightenment, sympathy, and social welfare'. Ethics and Social Welfare, 10(3), 211-223.

Heron, G. and Cassidy, C. (2018). 'Using practical philosophy to enhance the self-regulation of children in secure accommodation'. Emotional and Behavioural Difficulties, 23(3), 254269.

Lambek, P. and Antz, M. (1996). Tense past: Cultural essays in trauma and memory, London: Psychology Press.

Larkin, H. and Park, J. (2012). 'Adverse childhood experiences (ACEs), service use, and service helpfulness among people experiencing homelessness'. Families in society, 93(2), 8593.

Lasch, C. (1978). The culture of narcissism. New York, NY: Norton.

Levenson, J. (2017). 'Trauma-informed social work practice'. Social Work, 62(2), 105-113.

Loughlin, M. (2002). 'On the buzzword approach to policy formation'. Clinical Practice, 8(2), 229-242.

Lorenz, W. (2008). 'Paradigms and politics: Understanding methods paradigms in an historical context: The case of social pedagogy'. British Journal of Social Work, 38(4), 625644.

Luckhurst, R. (2013). The Trauma Question, London: Routledge.

Lukianoff, G. and Haidt, J. (2015). 'The coddling of the American mind'. The Atlantic, 316(2), 42-52. 
McGhee, J. and Waterhouse, L. (2020). 'Keep The Promise - or childcare without parents', https://sceptical.scot/author/janice-mcghee-elaine-waterhouse/ [accessed $17^{\text {th }}$ December 2020].

McLaughlin, K.A., Koenen, K.C., Hill, E.D., Petukhova, M., Sampson, N.A., Zaslavsky, A.M. and Kessler, R.C. (2013). 'Trauma exposure and posttraumatic stress disorder in a national sample of adolescents'. Journal of the American Academy of Child \& Adolescent Psychiatry, 52(8), 815-830.

Madsen, O. J. (2014). The therapeutic turn: how psychology altered Western culture. London: Routledge.

Maynard, B.R., Farina, A., Dell, N.A. and Kelly, M.S. (2019). 'Effects of trauma-informed approaches in schools: A systematic review'. Campbell Systematic Reviews, 15(1-2) e1018

Miller, G. (2008). 'Why Scottish "personal relations theory" matters politically'. Scottish Affairs, 62(1), 47-62.

Mooney, G. and Scott, G. (2016). 'Welfare, equality and social justice: Scottish independence and the dominant imaginings of the "New" Scotland'. Ethics and Social Welfare, 10(3), 239-251.

Munro, E. and Musholt, K. (2014). 'Neuroscience and the risks of maltreatment'. Children and Youth Services Review, 47(1), 18-26.

Murray, K. and Hunter Blackburn, L. (2019). 'Losing sight of women's rights: the unregulated introduction of gender self-identification as a case study of policy capture in Scotland'. Scottish Affairs, 28(3), 262-289.

NHS Education For Scotland (2020a). Transforming Psychological Trauma: National Trauma Training Programme Online Resources https://transformingpsychologicaltrauma.scot/media/s3rlizfi/nesd1334-national-traumatraining-programme-online-resources-0706.pdf [accessed 28th July 2021].

NHS Education for Scotland (2020b). National Training Plan, https://transformingpsychologicaltrauma.scot/working-together/pledge-for-partners/ [accessed $12^{\text {th }}$ Dec 2020].

NHS Education For Scotland and Scottish Government (2019). The Scottish Psychological Trauma Training Plan

https://transformingpsychologicaltrauma.scot/media/5lvh0lsu/trauma-training-planfinal.pdf [accessed $3^{\text {rd }}$ July 2021].

NICE (2018). Post-traumatic stress disorder (nice.org.uk) [accessed $3^{\text {rd }}$ July 2021]. 
OECD (2017). Preventing Policy Capture: Integrity in Public Decision Making, https://www.oecd.org/corruption/preventing-policy-capture-9789264065239-en.htm [accessed $7^{\text {th }}$ Dec 2020].

Parker, R and Bullock, R. (2017). 'A historical review of the concept of severe and multiple disadvantage and responses to it'. Adoption \& Fostering, 41(4), 307-330.

Paterson, L. (2000). 'Scottish democracy and Scottish utopias: The first year of the Scottish parliament'. Scottish Affairs, 33(1), 45-61.

Plafky, C. S. (2016). 'From Neuroscientific Research Findings to Social Work Practice: A Critical Description of the Knowledge Utilisation Process'. The British Journal of Social Work, 46(6), 1502-1519.

Radstone, S. (2007). 'Trauma theory: Contexts, politics, ethics'. Paragraph, 30(1), 9-29.

Rose, N. (1996). Inventing our Selves. Psychology, Power, and Personhood. Cambridge: Cambridge University Press.

Rutter, M. (1979). 'Protective factors in children's responses to stress and disadvantage', in Kent MW and Rolf JE (eds.), Primary Prevention in Psychopathology, Volume 3: Social competence in children. Hanover, NH: University Press of New England, pp. 49-74

Saunders, B. E., \& Adams, Z. W. (2014). 'Epidemiology of traumatic experiences in childhood'. Child and Adolescent Psychiatric Clinics of North America, 23, 167-184.

Scottish Government (2015). Survivor Scotland: Strategic Outcomes and Priorities 2015-17. https://www.gov.scot/publications/survivorscotland-strategic-outcomes-priorities-20152017/documents/ [accessed $27^{\text {th }}$ July 2021].

Scottish Government (2016). 'Swinney accepts inquiry chair resignation' . https://www.gov.scot/news/swinney-accepts-inquiry-chair-resignation/ [accessed $9^{\text {th }}$ Dec 2020].

Scottish Government (2017). A Nation with Ambition.

https://www.gov.scot/publications/nation-ambition-governments-programme-scotland2017-18/pages/9/ [accessed $9^{\text {th }}$ Dec 2020].

Smith, L. (2018). Adverse Childhood Experiences (ACEs): educational interventions, https://www.iriss.org.uk/resources/esss-outlines/aces [accessed 7th Dec 2018].

Spratt, T.; Devaney, J. Frederick, J. (2019). 'Adverse Childhood Experiences: Beyond Signs of Safety; Reimagining the Organisation and Practice of Social Work with Children and Families'. The British Journal of Social Work, 49(8), 2042-2058.

Spratt, T., \& Kennedy, M. (2021). 'Adverse Childhood Experiences: Developments in trauma and resilience aware services'. The British Journal of Social Work, 51(3), 999-1017. 
Sweeney, A., Clement, S., Filson, B. and Kennedy, A., (2016). 'Trauma-informed mental healthcare in the UK: what is it and how can we further its development?'. Mental Health Review Journal, 21(3), 174-192.

Tronto, J.C. (1993). Moral boundaries: A political argument for an ethic of care. London: Psychology Press.

Walsh, G.M. (2020). 'The arrival of the ACEs movement in Scotland: Policy entrepreneurship and critical activist responses'. Scottish Affairs, 29(4), 456-474.

Wastell, D. and White, S. (2017). Blinded by Science: The social implications of epigenetics and neuroscience. Bristol: Policy Press.

Wilton, J. and Williams, A. (2019) Engaging with complexity: providing effective traumainformed care for women. London: Centre for Mental Health and Mental Health Foundation/YoungMinds.

Zeedyck, S. (2019). 'Expert misses the point on child screening'. The Scotsman, $7^{\text {th }}$ April 2019.

https://www.scotsman.com/news/opinion/columnists/dr-suzanne-zeedyk-expert-missespoint-child-screening-1420328 [accessed 17th Dec 2020]. 